\title{
Validity of ECSC prediction equations for spirometric indices in Dutch conscripts
}

\author{
W.H. Stevens*, J.H. van Hartevelt**, P.E.K. The*, H.A.J. Smink*, Ph.H Quanjer**
}

Validity of ECSC prediction equations for spirometric indices in Dutch conscripts. W.H. Stevens, J.H. van Hartevelt, P.E.K. The, H.A.J. Smink, Ph.H Quanjer. CERS Journals Ltd 1994.

ABSTRACT: A study was performed to determine whether prediction equations issued by the European Community for Steel and Coal (ECSC) and the European Respiratory Society (ERS) fit spirometric data in young adult males. The study comprised 246 randomly selected Dutch conscripts, who participated in the study on the basis of informed consent.

A questionnaire was used to assess respiratory symptoms and smoking habits. Maximal expiratory flow-volume curves were obtained with a rolling seal spirometer, and summary statistics selected according to ECSC/ERS recommendations. In addition, standing height and body weight were obtained.

We analysed the data of $\mathbf{1 0 0}$ conscripts of European descent, with no history of respiratory symptoms. They were all life-long nonsmokers. Their mean (sD) age was 18 (0.12) yrs (range 17.9-19.0 yrs), with a mean (SD) standing height of 1.84 (0.06) $\mathrm{m}$ (range 1.68-2.00 m). The data for forced vital capacity (FVC), forced expiratory volume in one second $\left(\mathrm{FEV}_{1}\right)$ and maximal mid-expiratory flow (MMEF) agreed well with ECSC predictions; $95 \%$ confidence intervals $(95 \% \mathrm{CI})$ of differences between measured and predicted values were -0.174 to $0.044 l,-0.012$ to 0.174 $l \cdot \mathrm{s}^{-1}$ and $\mathbf{- 0 . 1 1 4}$ to $0.302 l \cdot \mathrm{s}^{-1}$, respectively. Peak expiratory flow was systematically larger than predicted, as was $\mathrm{FEV}_{1} \% \mathrm{FVC}\left(95 \% \mathrm{CI} 0.74\right.$ to $1.31 l \cdot \mathrm{s}^{-1}$ and 2.50 to $5.24 \%$, respectively), due to the intercept being inappropriate. The residual standard deviation in the conscripts was somewhat less than in the ECSC/ERS predictions equations, except for peak expiratory flow (PEF). The percentages of observations below the predicted lower limit were $9 \%$ for $\mathrm{FVC}, 5 \%$ for $\mathrm{FEV}_{1}, 2 \%$ for $\mathrm{FEV} \% \mathrm{FVC}$, $2 \%$ for PEF, and $4 \%$ for MMEF.

We conclude that the ECSC/ERS recommendations are satisfactory for $\mathrm{FEV}_{\text {, }}$, FVC and MMEF. However, FEV ${ }_{1} \% \mathrm{FVC}$ and PEF are systematically higher than predicted, but this does not preclude the use of prediction equations for diagnostic and discriminatory purposes.

Eur Respir J., 1994, 7, 29-34.

Lung volumes and forced ventilatory flows are routinely assessed in patients with suspected obstructive lung disease. In particular, forced expiratory volume in one second $\left(\mathrm{FEV}_{1}\right)$, forced vital capacity $(\mathrm{FVC})$, peak expiratory flow (PEF) and forced expiratory flow during the middle half of the FVC (MMEF) are often used for that purpose. Some laboratories also use the maximal expiratory flow at 75,50 or $25 \%$ of the $\mathrm{FVC}\left(\mathrm{MEF}_{75}, \mathrm{MEF}_{50}\right.$ and $\mathrm{MEF}_{25}$, respectively) in lung function assessment. Reference values for the 18-20 year age range are scarce, since this age group tends to be excluded in studies both on adolescents and adults. In 1983, a working party of The European Community for Steel and Coal (ECSC) issued recommendations on reference values for ventilatory indices [1], and suggested that between the ages $18-25$ yrs cross-sectionally there is no change in ventilatory function, so that an age of 25 yrs can be used in the regression equations. Recently the ECSC and European Respiratory Society (ERS) updated the recommendations,
*Dept of Medical Affairs for Conscripts, Ministry of Defense, The Netherlands. **Physiology Dept, Leiden University, Leiden, The Netherlands.

Correspondence: Ph.H. Quanjer

Physiology Dept

P.O. Box 9604

2300 RC Leiden

The Netherlands

Keywords: Flow-volume curve lung function

reference values

Received: June 291992

Accepted after revision July 201993

This study was supported by grant 7280 / 03/013 of the European Community for Steel and Coal. but those for reference values were unaltered [2]. However, there is evidence which suggests that lung volumes and forced ventilatory flows in males increase up to 25-30 yrs [3-10], so that the validity of this recommendation can be questioned.

The present study was designed to assess the validity of the ECSC recommendations on reference values in young male adults. Subjects included in this study were conscripts, who had received a call up for the mandatory medical examination at age 18 yrs. They were studied at one of the examination centres of the Armed Forces.

\section{Methods}

Subjects

As only males are conscripted into the army, all subjects participating in the study were males. The participants 
were randomly selected upon reporting at the desk at the medical examination centre for conscripts in Amsterdam. Each person participated voluntarily in the tests of ventilatory function, after being informed of the objectives. Spirometric tests were performed on the day of their medical testing in the period April-July 1991, on working days between 9 am and 4 pm.

Subjects were included in the study if they met the following criteria: 1) lifetime nonsmoker; 2) no symptoms of lung, heart or chest disease in the past of present; 3) of European descent; 4) having Dutch nationality; and 5) producing at least three technically satisfactory maximum expiratory flow-volume (MEFV) curves. The study was approved by the Medical Ethics Committees of the Armed Forces and the Academic Hospital of Leiden University.

\section{Data collection}

Each of the subjects filled out a self-administered Medical Research Council (MRC)-ECSC questionnaire [11], which formed the basis for assessing the respiratory health status. Standing height was measured to the nearest $\mathrm{mm}$ without shoes, and weight was measured (in $\mathrm{kg}$ ) without shoes and with light indoor clothing

Spirometry was performed with a Mijnhardt rolling seal spirometer (Vicatest type 5) fitted with a pulse encoder, which replaced the standard potentiometer. The encoder produces a pulse of $5 \mathrm{~V}$ when the volume changes by 20 $\mathrm{ml}$. A second pulse from the pulse encoder, which was out of phase with the first, was used to discriminate between inspiration and expiration. Sampling was initiated by the start of the forced expiratory manoeuvre, and terminated when there had been no volume change in 0.3 s. The spirometer was connected to a computer via a LabMaster Data Acquisition System (Scientific Solutions). The time between two pulses of the pulse-encoder was determined with a resolution of $10 \mathrm{~ms}$. The flow was obtained by differentiating the volume change with respect to time. A thermometer with digital display was fitted into the spirometer, so that its interior temperature could be read during measurements.

Prior to the study, the equipment had been validated; the spirometer had a frequency-response flat to $20 \mathrm{~Hz}$ sufficiently high to comply with ECSC $[1,2]$ and American Thoracic Society (ATS) [12] recommendations. The equipment was calibrated weekly by means of a $3 l$ calibrated syringe; the readings were stable, and therefore no parameter was changed during the study.

Prior to spirometric measurements, the procedure was explained and demonstrated to each subject. In the case of faulty manoeuvres, the display of the flow-volume loop was helpful in explaining how to improve the performance. All measurements were performed on seated subjects, sitting upright, and fitted with a noseclip. A minimum of three and a maximum of five technically acceptable flow-volume curves was obtained in each subject. From each set of flow-volume curves, a composite MEFV-curve was generated by the computer. This curve comprised the largest values for FVC and PEF, and the largest values of flows derived from curves with an FVC within $5 \%$ of the largest FVC, according to recommendations
$[1,2]$. The MMEF is similarly the largest value from an FVC within $5 \%$ of the largest FVC, and the $\mathrm{FEV}_{1}$ the largest value recorded.

All volumes and flows have been corrected to body temperature and pressure, saturated (BTPS) conditions.

\section{Data analysis}

Since all subjects were less than 25 yrs old, predicted values were obtained by substituting $25 \mathrm{yrs}$ in the prediction equations, in keeping with ECSC recommendations $[1,2]$. We then computed the difference between measured and predicted values for each index. The distribution of these residuals was then studied, i.e. their mean and standard deviation. In the case of a good fit to the ECSC predictions, the mean comes to nil, and the standard deviation is equal to the residual standard deviations (RSD) quoted in the ECSC report $[1,2]$. In keeping with the ECSC recommendation, the lower 5th percentile was computed by subtracting $1.64 \times \mathrm{RSD}$ from the predicted value; this value was then compared to the 5 th percentile actually observed in this population, and the percentage of subjects that fell below the ECSC 5th percentile. In addition, spirometric indices were regressed on standing height, as well as on standing height and body mass index (BMI). BMI is conventionally taken to be body weight (W) divided by height $(\mathrm{H})$ squared; however, in previous work on adolescents, we had observed that BMI still correlated with standing height. In order to remove any correlation between height and BMI, we therefore computed the best fit between $\log$ (weight) and $\log$ (height) of the form $\log (\mathrm{W})=\mathrm{a}+\mathrm{k} \times \log (\mathrm{H})$, and used $\mathrm{BMI}=\mathrm{W} / \mathrm{H}^{\mathrm{k}}$ in further analyses. Since the standard deviation of age came to only $0.12 \mathrm{yrs}$, age was not used in any of the computations. Statistical analysis was performed with the Number Cruncher Statistical System (NCSS) package [13].

\section{Results}

A total of 294 subjects was selected to take part in the study. Two persons refused to participate; six persons, who had agreed to participate, could not be tested because the time schedule for the medical examination was not compatible with that of the spirometric measurements. The data of 17 subjects could not be used, because they did not produce three acceptable forced vital capacity manoeuvres. One hundred subjects met the requirement that they never had respiratory symptoms, had been lifetime nonsmokers, were of Caucasian extraction, and had Dutch nationality (reference group). The remaining 169 subjects did not meet these criteria. The subjects lived both in urban and rural environments.

The mean age (SD) of the 100 reference subjects was $18.0(0.12)$ yrs (range 17.9-19.0 yrs), the mean height 1.84 (0.06) $\mathrm{m}$ (range (1.676-1.995 $\mathrm{m}$ ), and the mean body mass 73.1 (9.2) kg (range 50-98 kg). The relationship between body mass in $\mathrm{kg}(\mathrm{W})$ and standing height in $\mathrm{m}$ (H) was: $\mathrm{W}=24.16 \times \mathrm{H}^{1.81}(\mathrm{r}=0.4891)$. For each individual, the BMI was therefore obtained as $\mathrm{W} / \mathrm{H}^{1.81}$; the mean (SD) was 24.30 (2.73), and the range 18.57-34.25. 
Table 1. - Regression models of relationship between spirometric indices and anthropometric variables

\begin{tabular}{|c|c|c|c|c|c|}
\hline \multirow[b]{2}{*}{ Index } & \multicolumn{5}{|c|}{ Regression coefficients } \\
\hline & Intercept & Height & BMI & RSD & $\mathrm{r}$ \\
\hline $\mathrm{VCl}$ & 27 & 6 & 6 & + & 0.59 \\
\hline $\mathrm{FEV}_{1} l$ & & +4.045 & & 459 & - \\
\hline $\mathrm{EF} l \cdot \mathrm{s}^{-1}$ & -3.283 & +5.676 & 0.174 & .393 & 0.3945 \\
\hline MMEF $l \cdot \mathrm{s}^{-1}$ & -2.811 & +3.577 & $3 *$ & 1.040 & 0.2640 \\
\hline $\mathrm{MEF}_{75} l \cdot \mathrm{s}^{-1}$ & +2.487 & $+1.620 * *$ & +0.136 & 1.470 & 0.2546 \\
\hline $\mathrm{MEF}_{50} l \cdot \mathrm{s}^{-1}$ & -3.260 & +4.0 & +0. & .334 & .2579 \\
\hline \multirow[t]{2}{*}{$\mathrm{MEF}_{25} l \cdot \mathrm{s}^{-1}$} & -4 & $+38,-$ & & 9 & 2750 \\
\hline & \multicolumn{5}{|c|}{ Regression coefficients } \\
\hline Index & 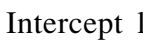 & $\ln ($ Height $)$ & BMI & RSD & $\mathrm{r}$ \\
\hline & & & & & \\
\hline & -0.431 & +1.8 & & 0.1001 & 0.5784 \\
\hline $\ln (\mathrm{PEF})$ & +0.622 & +0.962 & & 0.12 & 0.3979 \\
\hline $\ln (\mathrm{MMEF})$ & -0.152 & +1.3 & +0.3 & 0.2099 & 0.2640 \\
\hline $\ln \left(\mathrm{MEF}_{75}\right)$ & +0.645 & $+0.435^{* *}$ & +0.391 & 0.1784 & 0.2508 \\
\hline $\ln \left(\mathrm{MEF}_{50}\right)$ & -0.034 & $+1.236^{*}$ & +0.351 & 0.2252 & 0.2498 \\
\hline $\ln \left(\mathrm{MEF}_{25}\right)$ & -0.633 & +2.181 & $+0.147 * *$ & 0.2752 & 0.2704 \\
\hline
\end{tabular}

*: $0.10>\mathrm{p}>0.05 ; * * \mathrm{p}>0.10$. BMI: $\mathrm{W} / \mathrm{H}^{1.81}$, where $\mathrm{W}=$ weight in $\mathrm{kg}$ and $\mathrm{H}=$ stature in metre; $\mathrm{RSD}$ : residual standard deviation; $\mathrm{r}$ : correlation coefficient; FVC: forced vital capacity; $\mathrm{FEV}_{1}$ : forced expiratory flow volume in one second; PEF: peak expiratory flow; MMEF: maximal mid-expiratory flow; $\mathrm{MEF}_{75}, \mathrm{MEF}_{50}$ and $\mathrm{MEF}_{25}$ : maximal expiratory flow at $75 \%, 50 \%$ and $25 \%$ of $\mathrm{FVC}$, respectively.

The following models were tested:

$$
\begin{gathered}
\mathrm{Y}=\mathrm{a}_{1}+\mathrm{b}_{1} \times \mathrm{H}+\mathrm{c}_{1} \times \mathrm{BMI} \\
\ln \mathrm{Y}=\mathrm{a}_{2}+\mathrm{b}_{2} \times \ln \mathrm{H}+\mathrm{c}_{2} \times \mathrm{BMI} \\
\ln \mathrm{Y}=\mathrm{a}_{3}+\mathrm{b}_{3} \times \mathrm{H}+\mathrm{c}_{3} \times \mathrm{BMI}
\end{gathered}
$$

where $\mathrm{Y}=$ lung function index. The results obtained with the different models are given in table 1. The explained variance and the fit to model (2) was nearly identical to that of model (3); hence, results with the latter approach are not included in the table. FEV $\%$ FVC was not correlated to either height, age or BMI. PEF, MMEF, $\mathrm{MEF}_{75}$, $\mathrm{MEF}_{50}$ and $\mathrm{MEF}_{25}$ correlated poorly with standing height: the explained variance was between 6 and 16\% (table 1).

Table 2. - Comparison of regression coefficient of ventilatory function on standing height $(95 \%$ confidence interval) in the present study and that in prediction equations $[1,2]$

\begin{tabular}{lcc}
\hline Index & $95 \%$ CI & ECSC \\
\hline FVC & $3.89-7.39$ & 5.76 \\
FEV $_{1}$ & $3.02-6.01$ & 4.30 \\
MMEF & $0.23-6.84$ & 1.94 \\
PEF & $0.94-8.70$ & 6.14 \\
MEF & $-3.23-6.30$ & 5.46 \\
$M_{75}$ & $-0.03-8.30$ & 3.79 \\
$M_{50}$ & $1.08-6.61$ & 2.61 \\
\hline
\end{tabular}

95\% CI: 95\% confidence interval; ECSC: European Community for Steel and Coal. For further abbreviations see legend to table 1 .
Table 3. - Difference between observed and predicted values for ventilatory indices, and comparison of residual standard deviation (RSD) in present study and in ECSC/ERS document $[1,2]$

\begin{tabular}{lcccc}
\hline Index & Mean & $95 \% \mathrm{CI}$ & \multicolumn{2}{c}{ RSD } \\
& & & Conscripts & ECSC \\
\hline FVC $l$ & -0.07 & $-0.17-0.04$ & 0.55 & 0.61 \\
FEV $_{1} l$ & +0.08 & $-0.01-0.17$ & 0.47 & 0.51 \\
FEV $_{1} \% \mathrm{FVC} \%$ & +3.87 & $+2.50-5.24$ & 6.91 & 7.17 \\
PEF $l \cdot \mathrm{s}^{-1}$ & +1.02 & $+0.74-1.31$ & 1.46 & 1.21 \\
$\mathrm{MMEF} l \cdot \mathrm{s}^{-1}$ & +0.09 & $-0.11-0.30$ & 1.04 & 1.04 \\
$\mathrm{MEF}_{75} l \cdot \mathrm{s}^{-1}$ & -0.06 & $-0.37-0.23$ & 1.52 & 1.71 \\
$\mathrm{MEF}_{50} l \cdot \mathrm{s}^{-1}$ & +0.59 & $+0.32-0.85$ & 1.34 & 1.32 \\
$\mathrm{MEF}_{25} l \cdot \mathrm{s}^{-1}$ & +0.51 & $+0.33-0.68$ & 0.88 & 0.78
\end{tabular}

ERS: European Respiratory Society. For further abbreviations see legends to table 1 and 2 .

The regression coefficients for standing height were not significantly different from those in the ECSC document (table 2). In keeping with this, the difference between actual and predicted value was not related to standing height for any of the flow-volume indices $(0.1053$ $<\mathrm{p}<0.9086$ ).

Table 3 summarizes the difference between measured and predicted values. The standard deviations about the mean were similar to those in the ECSC recommendations, which were generally somewhat larger. There were no systematic differences between measured and predicted FVC, FEV ${ }_{1}$, and MMEF, but observed values for PEF and $\mathrm{FEV}_{1} \% \mathrm{FVC}$ were systematically higher than those predicted by the ECSC (table 3).

The specificity of tests, i.e. the proportion of subjects correctly identified as forming part of the reference population, is influenced by the distribution of test results. The lower 5th percentiles according to the ECSC document, the actual 5th percentile observed in the 100 subjects, and the number of subjects in whom measured values fell below the lower limit recommended by the ECSC are shown in table 4. The specificity varied between 91\% (FVC) and 99\% $\left(\mathrm{MEF}_{25}\right)$ (table 4).

Table 4. - Comparison of lower 5th percentiles (actual - predicted value) according to ECSC/ERS document and that observed in the 100 conscripts, and the percentage of subjects falling below the lower ECSC/ERS limit

\begin{tabular}{lccc}
\hline Index & $\begin{array}{c}\text { Actual } \\
\text { percentile }\end{array}$ & $\begin{array}{c}\text { Predicted } \\
\text { lower limit }\end{array}$ & $\%$ subjects \\
\hline FVC $l$ & -1.333 & -1.000 & 9 \\
FEV $_{1} l$ & -0.859 & -0.839 & 5 \\
FEV $_{1} \% \mathrm{FVC} \%$ & -9.53 & -11.79 & 2 \\
PEF $l \cdot \mathrm{s}^{-1}$ & -1.57 & -1.99 & 2 \\
$\mathrm{MMEF} l \cdot \mathrm{s}^{-1}$ & -1.666 & -1.710 & 4 \\
$\mathrm{MEF}_{75} l \cdot \mathrm{s}^{-1}$ & -2.500 & -2.812 & 4 \\
$\mathrm{MEF}_{50} l \cdot \mathrm{s}^{-1}$ & -1.648 & -2.171 & 3 \\
$\mathrm{MEF}_{25} l \cdot \mathrm{s}^{-1}$ & -0.811 & -1.283 & 1 \\
\hline
\end{tabular}

For abbreviations see legends to tables $1-3$. 


\section{Discussion}

In the Netherlands, all boys are, in principle, eligible to be conscripted into the army. Hence, each of them is medically examined. Therefore, the subjects participating in this study form an unselected sample of the population of conscripts. In these naive subjects, we generally found satisfactory agreement between the predicted and observed values for most spirometric indices. Whilst the age coefficient could not be tested, the regression coefficient of ventilatory function on standing height in the ECSC document appears to be compatible with that in this population of young adults. The most commonly used indices, i.e. $\mathrm{FEV}_{1}$ and $\mathrm{FVC}$, agree remarkably well with the predicted values, so that these predictions appear to be quite valid for screening purposes and for clinical use. However, the intercept for PEF is about $1 l \cdot \mathrm{s}^{-1}$ too low in the ECSC prediction equations, and $\mathrm{FEV}_{1} \% \mathrm{FVC}$ about $3.9 \%$ too low (table 3 ). On that account, $2 \%$ rather than $5 \%$ of subjects have a value for PEF and $\mathrm{FEV} \% \mathrm{FVC}$ below the recommended lower limit of normal. For FVC this comes to $9 \%$; this is due to a group of subjects who seem to form a population distinct for the other reference subjects (fig. 1 ).

The fair overall agreement between ECSC predictions and the observed values, whilst satisfactory and reassuring, may not hold true for populations elsewhere in Europe. The ECSC equations derived from a mix of historic data, which showed considerable discrepancies [1]; the original material had been collected up to three decades ago, when the selection of subjects, equipment, measurement techniques, procedures adopted, etc. must have been different from that in the present study. In addition, cohort effects [14], and the changing relationship between trunk and total height [15] of successive birth cohorts, might have led to a changing relationship between standing height and ventilatory function. On the other hand, MERKUS and QuANJER [16] found no evidence of a time-related trend in prediction equations for children and adolescents [16].

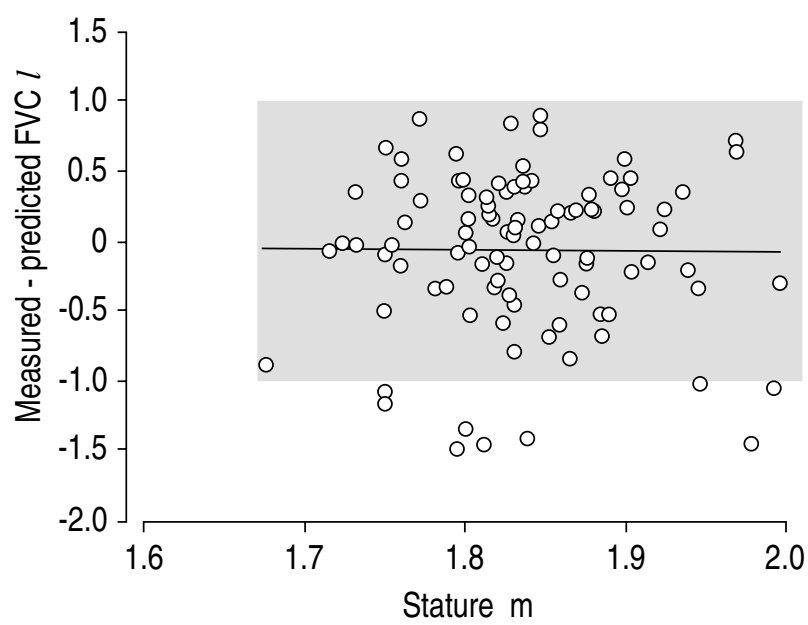

Fig. 1. - Relationship between measured and predicted FVC [1, 2], plotted as a function of stature. Solid line is the regression line of actual minus predicted FVC on stature. The boxed area delineates the 5 th and 95 th percentile according to $[1,2]$. FVC: forced vital capacity.
In general, the variance explained by height is low, and less than that reported in adults in the literature. This is probably, in part, due to the small range in height in the present study. In the age range $20-70$ yrs there is a greater scatter in standing height, due to older generations being systematically smaller than young adults. In the present population the range in standing height is 32 $\mathrm{cm}$, whilst in a previous study of Dutch males aged 20-70 yrs the range was $44 \mathrm{~cm}$ [1]. Non-linear relationships between the ventilatory index and independent variables (models (2) and (3)) have no advantage over simple, linear models (table 1), a conclusion reached previously by DROUET et al. [17].

The body mass index contributed significantly to reducing the variance of spirometric indices, except for effort independent flows. This finding cannot be interpreted unequivocally: a high value for this index may be due to increased body fat, or greater muscularity; a low one may be associated with a very slender body build or long legs for height [18]. Hence, it is not clear whether the contribution of the BMI primarily reflects variability in muscularity; the positive correlation of BMI to effort dependent indices of ventilatory function suggests that a more athletic body build and greater muscle force are the most plausible explanations. A more direct measure of the contribution of respiratory muscle strength can be derived from measurement of maximal inspiratory and expiratory pressure, at different lung volumes. Thus, LEECH et al. [19], Gaultier and ZinMan [20], and Schrader et al. [21] showed that muscularity does contribute, somewhat, to explaining differences in ventilatory function between subjects.

$\mathrm{FEV}_{1} \% \mathrm{FVC}$ was systematically higher in conscripts than predicted, so that only $2 \%$ of the values fell below the predicted lower limit of normal; this may have bearing in clinical practice and in screening, as the index is often used. If the prediction is too low, then the specificity of the test increases, i.e. a greater proportion of healthy subjects is correctly identified. On the other hand, the sensitivity, i.e. the proportion of patients with airflow limitation correctly identified, diminishes likewise. The decrease in the proportion of false positive test results is, therefore, associated with an increase in the proportion of false negative test results. In fact, the recommendation to substitute 25 yrs in the prediction equation for people younger than 25 yrs may not be logical. This is because, in many studies, the $\mathrm{FEV}_{1} / \mathrm{FVC}$ ratio has been found to decrease steadily in adolescents, even though $\mathrm{FEV}_{1}$ and FVC increase due to growth (overview in [22]). It is therefore likely that this decrease continues up to age $25 \mathrm{yrs}$, and beyond. If, on that account, the actual age is substituted in the prediction equation, the lower limit of normal in the conscripts changes to $-10.79 \%$ below the predicted mean $\mathrm{FEV} \% \mathrm{FVC}$ (fairly close to that predicted by the ECSC) (table 4), and 3\% have values below the lower limit of the ECSC; this represents only a small change in this material. We suggested that, in practice, reliance should be placed primarily on the $\mathrm{FEV}_{1}$ and $\mathrm{FVC}$, and the ratio be considered only secondarily, adopting a 5 th percentile which is $10 \%$ below the predicted $\mathrm{FEV}_{1} \% \mathrm{FVC}$. However, further studies are required 
to show that our findings also apply to other populations, before undue reliance is placed on the results of the present study.

The recorded peak expiratory flow was systematically higher than predicted. This might, in principle, be due to the rolling seal spirometer being unsuitable for measurements of PEF. However, the frequency response of the instrument has been shown to be sufficient for measurements of PEF [23-25]. It is more likely that the ECSC predictions for PEF are too low when applied to pneumotachometers and spirometers with a fast rise time, since the peak flow meter underestimates PEF if it is reached in less than $100 \mathrm{~ms}$ [26]. We found, in a separate study, that $50 \%$ of adolescents reach PEF in less than $100 \mathrm{~ms}$ (unpublished observations). The ECSC summary equations derive from a mix of pneumotachometer and peak flow meter recordings, and may, therefore, give values which are too low for low resistance instruments with a good dynamic response. In the updated standardization report, the ECSC and ERS recommend that more work is needed to establish acceptable reference equations for PEF, and our findings tend to support that view.

In general, flows towards the end of the forced vital capacity manoeuvre are greater than predicted (table 3 ). This reflects MEFV-curves which are more convex towards the volume axis than predicted in adults. This is compatible with increased stiffness of the thoracic cage during growth, so that residual volume in young adults is primarily determined by the elastic properties of the thorax; whilst in older subjects the elastic properties of the lung are a more important determinant [27]. Flows at specified percentages of the FVC are poorly predictable (table 1) (review in [1]); in addition, they are dependent on the FVC, which is itself influenced by both lung disease and extrapulmonary factors. This implies that these indices should not be used for screening purposes. Hence, we suggest that there is no purpose in supplying prediction equations for these indices, or in using them for screening purposes.

In conclusion, these data suggest that the ECSC summary equations for $\mathrm{FEV}_{1}$, FVC and MMEF are applicable in 18 year old healthy males, both for screening purposes and clinical work. The $\mathrm{FEV}_{1} / \mathrm{FVC}$ ratio in young subjects is systematically greater than predicted, but there are reasons to suggest that the actual age, rather than 25 yrs, should be substituted in the prediction equations. Flows towards the end of the forced vital capacity manoeuvre are systematically higher than predicted in young adults, but the usefulness of these indices is doubtful anyway, and, therefore, this finding is of little consequence.

Acknowledgements: The authors wish to thank R.P. de Groot, without whose support the study could not have been organized.

\section{References}

1. Quanjer $\mathrm{PhH}$ (ed). - Standardized lung function testing. Report Working Party "Standardization of Lung Function Tests", European Community for Steel and Coal.
Bull Eur Physiopathol Respir 1983; 19 (Suppl. 5): 1-95.

2. Quanjer PhH, Tammeling GJ, Cotes JE, Pedersen OF, Peslin R, Yernault J-C. - Lung volumes and forced ventilatory flows. Report Working Party "Standardization of Lung Function Tests", ECSC, Official Statement European Respiratory Society. Eur Respir J 1993; 6 (Suppl. 16): 5-40.

3. Schoenberg JB, Beck GJ, Bouhuys A. - Growth and decay of pulmonary function in healthy blacks and whites. Respir Physiol 1978; 33: 367-393.

4. Hurwitz S, Allen J, Liben A, Becklake M. - Lung function in young adults: evidence for differences in the chronological ages at which various functions start to decline. Thorax 1980; 35: 615-619.

5. Burrows B, Cline MG, Knudson RJ, Taussig LM, Lebowitz MD. - A descriptive analysis of the growth and decline of the FVC and $\mathrm{FEV}_{1}$. Chest 1983; 83: 717-724.

6. Dockery DW, Ware JH, Ferris BG, et al. - Distribution of forced expiratory volume in one second and forced vital capacity in healthy, white, adult never-smokers in six US cities. Am Rev Respir Dis 1985; 131: 511-520.

7. Burrows B, Lebowitz MD, Camilli AE, Knudson RJ. Longitudinal changes in forced expiratory volume in one second in adults. Methodological considerations and findings in healthy nonsmokers. Am Rev Respir Dis 1986; 133: 974-980.

8. Tager IB, Segal MR, Speizer FE, Weiss ST. - The natural history of forced expiratory volumes. Am Rev Respir Dis 1988; 138: 837-847.

9. Sherrill DL, Camilli A, Lebowitz MD. - On the temporal relationship between lung function and somatic growth. Am Rev Respir Dis 1989; 140: 638-644.

10. Kristufek P, Brezina M, Ciutti P, Strmen J, Mayer M. Reference values and modelling of lung function development as a transcendent function of age, body height and mass. Bull Eur Pathophysiol Respir 1987; 23: 139147.

11. Van der Lende R, Orie NGM. - The MRC-ECSC questionnaire on respiratory symptoms. Use in epidemiology. Scand J Respir Dis 1972; 53: 218-226.

12. ATS Statement. - Standardization of spirometry - 1987 update. Am Rev Respir Dis 1987; 136: 1285-1289.

13. Number Cruncher Statistical System. - JL Hintze, Kaysville, Utah, 1991.

14. Glindmeyer HW. - Predictable confusion. J Oсcиp Med 1981; 23: 845-849.

15. Tanner JM, Hayashi T, Preece M, Cameron N. - Increase in length of leg relative to trunk in Japanese children and adults from 1957 to 1977: a comparison with British and with Japanese Americans. Ann Hum Biol 1982; 9: 411423.

16. Merkus PJFM, Quanjer PhH. - Cohort effects and paediatric pulmonary reference values. Eur Respir J 1990; 3: 299s.

17. Drouet D, Kauffman F, Brille D, Lellouch J. - Valeurs spirographiques de référence. Modèles mathématiques et utilisation pratique. Bull Eur Physiopathol Respir 1980; 16: 747-767.

18. Garn SM, Leonard WM, Hawthorne VM. - Three limitations of the body mass index. Am J Clin Nutr 1986; 44: 996-997.

19. Leech JA, Ghezzo H, Stevens D, Becklake MR. Respiratory pressures and function in young adults. Am Rev Respir Dis 1983; 128: 17-23.

20. Gaultier C, Zinman R. - Maximal static pressures in healthy children. Respir Physiol 1983; 21: 45-61.

21. Schrader PC, Quanjer PhH, Olievier ICW. - Respiratory 
muscle force and ventilatory function in adolescents. Eur Respir J 1988; 1: 368-375.

22. Quanjer PhH, Stocks J, Polgar G, Wise M, Karlberg J, Borsboom G. - Compilation of reference values for lung function measurements in children. In: Quanjer $\mathrm{PhH}$, Helms P, Bjure J, Gaultier C, eds. Standardization of lung function tests in paediatrics Eur Respir J 1989; 2 (Suppl. 4): 184s-261s.

23. Peslin R. - Frequency response of pneumotachographs. Bull Physiopathol Respir 1972; 8: 1363-1376.

24. Kruyt EW, Van Hartevelt JH, Quanjer PhH, Douma JH. - Frequency requirements for pneumotachometers for recording maximum expiratory flow-volume curves. Bull Eur Physiopathol Respir 1982; 18: 42p-43p.

25. Peslin R, Jardin P. - Influence of second-order data filtering on common forced expiration indices. Clin Physiology 1983; 3: 123-130.

26. Miller M, Pedersen OF. - The characteristics and calibration of devices for recording peak expiratory flow. International workshop on peak expiratory flow. Brussels, September 1991.

27. Leith DE, Mead J. - Mechanisms determining residual volume of the lungs in normal subjects. J Appl Physiol 1967; 23: 221-227. 